\section{Tuberculose e leite: elementos para a história de uma polêmica}

\section{Tuberculosis and milk: elements of a polemic}

José Leopoldo Ferreira Antunes

Faculdade de Odontologia da

Universidade de São Paulo (FOUSP)

Av. Lineu Prestes, 2227

05508-900 São Paulo — SP Brasil leopoldo@usp.br

Mirtes de Moraes

Pontifícia Universidade Católica de São Paulo (PUC-SP) correalu@ig.com.br

Maria Gabriela Haye Biazevic

Universidade do Oeste de Santa Catarina (UNOESC), Campus Joaçaba gabriela@unoescjba.edu.br

Eliseu Alves Waldman

Faculdade de Saúde Pública da Universidade de São Paulo (FSP-USP) eawaldma@usp.br

Marcelo Oswaldo Alvares Corrêa

Instituto Adolfo Lutz (IAL-SP) Rua Cefelândia, 237 Sumaré 01255-030 São Paulo — SP
ANTUNES, J. L. F.; MORAES, M. de; BIAZEVIC, M. G. H.; WALDMAN, E. A. e CORREA, M. O. A.: 'Tuberculose e leite: elementos para a história de uma polêmica'. História, Ciências, Saúde-Manguinbos, vol. 9(3): 609-23, set.-dez. 2002.

Pode o ser humano contrair tuberculose pela ingestão do leite de vacas tuberculosas? São efetivos o diagnóstico e o controle da tuberculose bovina para a proteção da população humana? Questões como estas estiveram em pauta no pensamento médico paulistano no início do século XX. O presente estudo procurou reconstituir elementos da polêmica travada em São Paulo, com o intuito de incentivar a divulgação de dados suplementares sobre a matéria. Aqui são apresentadas indicações sintéticas das posições em confronto: de um lado, as preocupações em intensificar as ações de controle do gado tuberculoso; de outro, o cuidado de não prejudicar os criadores nacionais com a demanda de precaucões adicionais, as quais se temia serem lesivas à comercialização do produto. $\mathrm{O}$

acompanhamento das intervencões sobre o tema na imprensa médica permitiu identificar a preponderância da primeira posição, com conseqüências para o controle sanitário de alimentos.

PALAVRAS-CHAVE: tuberculose, tuberculose bovina, leite, gado, história da medicina.

ANTUNES, J. L. F.; MORAES, M. de; BIAZEVIC, M. G. H.; WALDMAN, E. A. e CORREA, M. O. A.: 'Tuberculosis and milk: elements of a polemic'

História, Ciências, Saúde-Manguinhos, vol. 9(3): 609-23, Sept.-Dec. 2002.

Can human beings get tuberculosis from the milk taken from cows infected with

tuberculosis? Are the diagnosis and control of cattle tuberculosis effective for the protection of human populations? Questions such as these were the main concern of doctors from São Paulo at the beginning of the twentieth century. The present study tried to recover elements from the polemic that took place in São Paulo, in order to encourage the coming up of complementary facts about such matter. The article presents some indicators of confronting positions: on one hand, the goal of intensifying the control of tuberculosis among the cattle; on the other hand, the attempt not to bring up any loss to national cattle raisers through the demand of additional precaution measures, which would affect the production and distribution of their products. Medical publications kept records of the interventions, which have allowed the author to identify the first position as the stronger one, which has brought up relevant consequences for the sanitary food control.

KEYWORDS: uberculosis, cattle tuberculosis, milk, cattle, history of medicine. 


\section{Introdução}

Z $\mathrm{m} 30$ e 31 de janeiro de 1903, exercendo a função de inspetor E sanitário, o médico Epiphanio Pedrosa foi à fazenda de Arnaldo Vieira de Carvalho, no Mandaqui, bairro atualmente já integrado à cidade de São Paulo, para aplicar o teste da tuberculina em 26 vacas. Obteve resultado positivo para duas delas, as quais separou para nova inoculação, declarando as demais não tuberculosas. O procedimento foi rejeitado por Arnaldo Vieira de Carvalho, com o argumento de que teria testado pessoalmente suas reses menos de dois meses antes, com tuberculina supostamente da melhor qualidade, produzida por Henrique Schaumann na botica Ao Veado D'Ouro, tradicional casa farmacêutica da cidade, não encontrando vacas tuberculosas.

Ante a reação, Epiphanio Pedrosa teve o cuidado de registrar em seu relatório que a tuberculina empregada pelo serviço público municipal era importada pela casa Baruel e fabricada por Robert Koch, "seu inventor, em seu próprio laboratório, da qual a Merck apenas tomou a si a parte comercial". Ademais, sublinhou, ele havia "injetado a diminuta dose de vinte centigramas", não sendo provável que em tão curto prazo, sem contágio, "as duas vacas ficassem tuberculosas" (São Paulo, 1903a).

O conflito marcava mais um lance da polêmica sobre a viabilidade da transmissão da tuberculose pelo leite de vaca, a qual mobilizou o meio médico paulistano, a imprensa diária e a esfera legislativa municipal em diferentes momentos das duas primeiras décadas do século XX. No mesmo período do episódio descrito, estava em seu apogeu o debate na Sociedade de Medicina e Cirurgia de São Paulo, opondo os médicos que atuavam no serviço público, que se esforçavam por ampliar o controle sanitário sobre alimentos, a Arnaldo Vieira de Carvalho, que apregoava a inocuidade da ingestão do leite de vacas tuberculosas e considerava desnecessárias as medidas específicas de controle sanitário. Além disso, cerca de dez dias antes, Arnaldo Vieira de Carvalho (1903a) havia publicado no jornal O Estado de S. Paulo seu voto discordante à posição preponderante no pensamento médico.

Protagonista da polêmica sobre tuberculose e leite em São Paulo, Arnaldo Vieira de Carvalho foi personalidade de grande projeção no meio médico paulista, tendo exercido um extenso rol de cargos e funções. Entre outras posições de destaque, ele ocupou a presidência da Sociedade de Medicina e Cirurgia de São Paulo em 1901 e 1906; fundou a Policlínica de São Paulo e a dirigiu em 1897 e 1906. Médico da Santa Casa desde 1889, ele assumiu a direção clínica do hospital central em 1894. Além disso, dirigiu o Instituto Vacinogênico de São Paulo de 1893 a 1913; colaborou na fundação (em 1911) e dirigiu o periódico Anais Paulistas de Medicina e Cirurgia; participou da fundação e do corpo docente da Faculdade de Medicina e Cirurgia de São Paulo, tendo dirigido a instituição de 1913 até sua morte, em 1920 (Guimarães, 1967; Mesquita, 1975). 
E, na condição de proprietário de terras, o médico - a quem as futuras gerações de paulistanos se acostumariam a chamar de "dr. Arnaldo", em função do importante complexo viário a que empresta seu nome - interveio diversas vezes na imprensa diária para defender pontos de vista de interesse para a pecuária. Proprietário da Leiteria Modelo, o dr. Arnaldo Vieira de Carvalho, o médico, tinha interesse na distribuição de leite na capital, e firmou sua posição como representante dos criadores de gado leiteiro, ao participar como membro, em 1906, do Conselho Consultivo dos Criadores do Estado de São Paulo (Ribeiro, 1993).

O objetivo do presente estudo é consolidar um registro preliminar da documentação e da literatura que puderam ser coligidas sobre o debate travado no meio médico paulistano a respeito do risco de transmissão da tuberculose pelo leite e sintetizar indicações analíticas sobre a inserção da polêmica no contexto organizacional da saúde no período. Desse modo, espera-se incentivar a apresentação de dados suplementares sobre a matéria, assim como a realização de novos estudos relacionando aspectos históricos sobre a questão em outras cidades brasileiras.

Para o retrospecto histórico da polêmica, pesquisou-se a Revista Médica de São Paulo, o acervo do jornal O Estado de S. Paulo, atas das sessões da Sociedade de Medicina e Cirurgia de São Paulo, anais da Câmara Municipal de São Paulo e papéis avulsos da Divisão do Arquivo Histórico do Departamento do Patrimônio Histórico da Prefeitura Municipal de São Paulo.

\section{Controle sanitário do gado tuberculoso}

Clemente Ferreira (1902) descreveu a adoção dos primeiros dispositivos legais de âmbito municipal instituindo a aplicação obrigatória do teste de tuberculina nas vacas leiteiras e o abate dos animais com diagnóstico positivo em 1897, no Rio de Janeiro, e em 1898, em São Paulo. A falta de rigor com que essas medidas foram aplicadas teria levado à adoção de seguidas providências legais nos anos seguintes. Em São Paulo, em 1903 e 1904, novos dispositivos legais reforçaram a obrigação do teste e determinaram que as vacas com reação positiva fossem marcadas a ferro com a letra ' $T$ ', retiradas dos estábulos e encaminhadas para abate no matadouro municipal. Determinavam ainda a realização de exames necroscópicos comprobatórios da infecção, para fins de registro e contraprova legal.

Epiphanio Pedrosa (1905) acusou a ampla disseminação da tuberculose bovina na cidade: em 1904, 17,8\% de 4.091 vacas examinadas apresentaram resultado positivo; $61,1 \%$ dos 660 criadores matriculados tiveram ao menos uma vaca com diagnóstico de tuberculose. Sem valor comercial, as vacas estigmatizadas eram vendidas a baixo preço, para reduzir os custos de pastagem. Desse modo, eram 
transferidas para as cidades do interior, onde continuavam transmitindo a zoonose; por insuficiente fiscalização, burlava-se a determinação legal do abate e favorecia-se a venda clandestina de carne e leite contaminados.

No mesmo período, o Serviço Sanitário esforçava-se por efetivar as medidas de controle da tuberculose bovina em São Paulo. Uma troca de ofícios entre Emílio Ribas, diretor da repartição, Adolpho Lutz, diretor do Instituto Bacteriológico, e o conselheiro Antônio da Silva Prado, prefeito municipal, indicava os procedimentos aplicados e exemplificava a documentação arquivada para controle e proteção do serviço público contra possíveis representações judiciais dos criadores.

Diretoria do Serviço Sanitário do Estado de São Paulo.

São Paulo, 9 de janeiro de 1903.

Cidadão,

Em resposta ao vosso ofício sob o no 485 , de 20 de outubro do ano próximo findo, pedindo para ser feito o exame bacteriológico das carnes e vísceras da vaca que, matriculada com o no 5.193 , devia ser abatida no Matadouro Municipal em virtude de ter-se verificado, pela inoculação da tuberculina, se achar a mesma afetada de tuberculose, transmito-vos, por cópia, o resultado do exame feito pelo dr. diretor do Instituto Bacteriológico do Estado.

Saúde e Fraternidade. O diretor, dr. Emílio Ribas.

Ao ilustre cidadão dr. prefeito municipal.

Instituto Bacteriológico do Estado de São Paulo

Of. no 110. São Paulo, 7 de janeiro de 1903.

Ao cidadão dr. diretor geral do Serviço Sanitário.

Devolvendo junto o oficio no 485 da Prefeitura Municipal, cumpre-me declarar que verifiquei, tanto pelo exame macro e microscópico, como pela inoculação em cobaias, que a referida vaca sofria de tuberculose das serosas e dos gânglios linfáticos.

Saúde e Fraternidade.

O diretor dr. Adolpho Lutz (São Paulo, 1903a).

O abate do gado tuberculoso colocou em pauta nos debates legislativos uma consideração a respeito do pagamento de indenização aos produtores que se sentiam lesados pela perda do animal. Em 1904, o preço de uma vaca oscilava de trezentos a oitocentos mil-réis, enquanto o litro de leite era vendido a quinhentos réis (Pedrosa, 1905). Burlando a determinação do abate, os proprietários tentavam comercializar as vacas marcadas com o 'T', aceitando até mais de 90\% de desvalorização no preço. Com o objetivo de suprimir o comércio ilegal e cedendo à pressão dos criadores, a prefeitura passou a indenizar 
em cem mil-réis cada rês abatida. A quantia, no entanto, foi considerada excessiva pela Câmara Municipal, que deliberou reduzir à metade a indenização.

O ressarcimento de cinqüenta mil-réis foi mantido até 1912, quando o assunto retornou à pauta da Câmara, por iniciativa de criadores que solicitavam aumento desse valor. Com a retomada do debate, os vereadores resolveram certificar-se quanto à efetividade do diagnóstico da tuberculose bovina e dirigiram à Sociedade de Medicina e Cirurgia de São Paulo a seguinte questão: "É um dogma inquestionável a afirmação de que a inoculação da tuberculina só produz reação nos animais tuberculosos?" Registrada nos anais da Câmara Municipal, a resposta foi inequívoca e enfática:

Essa questão já foi discutida amplamente em 1903 aqui na Sociedade e à Câmara Municipal foram remetidas as conclusões sobre o assunto. Essa é uma questão resolvida; hoje não há dúvida sobre a ação da tuberculina no diagnóstico da tuberculose incipiente nos bovídeos (dados do dr. Pedrosa - 15.192 bovídeos examinados, 2.351 prova positiva, autopsia indicou lesão tuberculosa). À vista do exposto, somos de opinião que devam ser continuadas as inoculações com a tuberculina, feitas com os cuidados precisos, para melhor êxito e demonstração do valor incontestável desta medida preventiva e útil (São Paulo, 1913).

Desfavorável à demanda, a Comissão de Finanças da Câmara cogitou o cancelamento da indenização, tendo em vista que, nas palavras de um de seus membros, o vereador Mário do Amaral, "uma vaca tuberculosa não vale nem mesmo essa quantia". Mesmo assim, o presidente da comissão - o vereador Armando Prado - resolveu manter o valor original, com a finalidade de evitar reclamações. Além de solicitar o indeferimento da petição dos criadores, a Comissão de Finanças propôs a inclusão de cláusula restritiva à indenização de vacas compradas há menos de três meses, com a finalidade de evitar fraudes contra o erário, pois acusava-se a importação dolosa de gado tuberculoso da Argentina e de outros municípios do interior do estado, provocada pelo pagamento da indenização. Aventada pelo vereador Alcântara Machado como medida que evitaria "todos os perigos do leite", a pasteurização obrigatória não chegou a ser proposta no parecer.

Apesar das ponderações apresentadas, a Comissão de Justiça da Câmara Municipal retirou a restrição de prazo para a entrada na cidade dos animais passíveis de serem indenizados pela prefeitura e aprovou o aumento da quantia para cem mil-réis.

\section{Motivações preliminares da polêmica}

Diversos fatores e precedentes motivaram a discussão no meio médico. De um lado, a esfera pública esforçava-se por ampliar sua intervenção, com a finalidade de controle da tuberculose bovina, 
provocando atritos entre inspetores sanitários e pecuaristas. De outro, os estudos sobre a profilaxia da tuberculose na imprensa médica sempre dedicavam algum item ao tema do consumo de leite contaminado. E, fazendo justiça ao grave quadro de disseminação da doença, que respondia por quase $10 \%$ dos óbitos ocorridos na cidade durante o período (Antunes et al., 1999), as comunicações médicas sobre tuberculose eram freqüentes.

Na condição de inspetor sanitário e médico ligado ao serviço público, Victor Godinho assumiu posição de destaque na polêmica envolvendo a transmissão da tuberculose via leite de vaca, em oposição a Arnaldo Vieira de Carvalho. Importante nome do meio médico paulista, ele participou da fundação da Escola de Farmácia de São Paulo, em 1898, e exerceu a função docente na disciplina de higiene e microbiologia até sua morte, em 1923. Escreveu um compêndio de bacteriologia que foi importante referência didática no período. Junto com Arthur Vieira de Mendonça, fundou a Revista Médica de São Paulo, em 1898, e dirigiua até seu encerramento, cerca de vinte anos depois. Atuou como médico interno do hospital de isolamento da capital (o atual Instituto de Infectologia Emílio Ribas) desde 1901 e substituiu Cândido Espinheira na direção do estabelecimento, em 1915, até se aposentar, em 1919.

Sócio fundador da Liga Paulista contra a Tuberculose, Victor Godinho foi seu presidente pelo período de um ano. Além disso, presidiu a Sociedade Estrada de Ferro Campos do Jordão, conseguindo, com o apoio de Emílio Ribas, os recursos para a construção da ferrovia mais tarde encampada pelo estado, a qual favoreceu o acesso ao sítio de relevo culminante do território paulista, onde se instalaram diversas unidades de atendimento aos tuberculosos (Brasiliense, 1923; São Paulo, 1923).

Desde o final do século XIX, Victor Godinho havia publicado várias monografias sobre prevenção e tratamento da doença, nas quais reunira evidências da literatura médica internacional sobre o contágio por ingestão de leite e carne contaminados. Desse modo, ele expunha sua crença na transmissibilidade do bacilo através dos alimentos, principalmente o leite e a carne em conserva ou embutidos, que se costumavam ingerir sem o devido cozimento (Godinho, 1900; Godinho et al., 1899a). Segundo seus estudos, o cuidado com o leite deveria ser redobrado, pois era "o alimento por excelência das crianças, das pessoas debilitadas, em condições perfeitas para a aquisição da moléstia" (idem, 1899b), e as vacas tuberculosas em geral eram gordas e de aparência sadia. Embora explicitassem a referência à capacidade de transmissão da doença bovina para o ser humano através da "aquisição da moléstia pelo aparelho digestivo", à "penetração do germe da moléstia pelo estômago e intestino", os autores não esclareciam as dúvidas correntes quanto à identidade da doença no gado e no homem. Também Coriolano Burgos (1900) apresentou comunicação sintetizando o conhecimento disponível sobre a tuberculose, na qual incluía extensa 
${ }^{1}$ Trata-se de 'Mammite tuberculeuse experimentale chez la vache et la chèvre em lactation" (Paris, XIII Congrès International d'Hygiene, Section de Pathologie Genérale, 1900). Ver Godinho (1903).

\footnotetext{
${ }^{2}$ O leitor interessado no tema poderá encontrar uma síntese da literatura internacional produzida pela polêmica envolvendo tuberculose e leite no estudo de Barbara Gutmann Rosenkrantz (1985).
}

consideração sobre a carne e o leite, atribuindo-lhes a capacidade de veicular a doença.

Além disso, as proposições que buscavam integrar aspectos específicos do controle de alimentos ao conjunto de medidas profiláticas da doença vinham de encontro às reclamações dos inspetores sanitários quanto ao "estado primitivo" das instalações ocupadas pelo matadouro municipal, "deficiência de laboratórios para exames, vícios de construção, incúria em fiscalização etc." (São Paulo, 1901), assuntos já discutidos em sessões anteriores da Sociedade de Medicina e Cirurgia.

Outro fator que pesou para a polêmica em São Paulo foi o interesse suscitado pelos argumentos apresentados ao debate travado no meio médico internacional, opondo Edmond Nocard, precursor dos estudos que levariam à produção da vacina BCG, e Robert Koch, responsável pelo isolamento do bacilo da tuberculose em 1882. Nocard havia comunicado ao $13^{\circ}$ Congresso Internacional de Higiene ter conseguido "tuberculinizar vitelos por meio de injeções intravenosas de bacilos de tuberculose humana" (Nocard apud Godinho, 1903). ${ }^{1}$ Enquanto isso, em um "erro que demorou 15 anos para ser retificado", conforme a avaliação de Hancox (2002), Koch teria asseverado no mesmo evento "a diversidade da tuberculose bovina e humana e que o uso de carnes e leite de animais tuberculosos era inócuo, devendo ser abandonadas as medidas profiláticas empregadas até então" (Koch apud Carvalho, 1903b; Koch apud Azevedo, 1903).

Em 1906, a Revista Médica de São Paulo publicou comunicação apresentada no ano anterior aos Annales de l'Institute Pasteur por Albert Léon Charles Calmette e Camille Guérin, na qual eles reforçavam o ponto de vista de Nocard e afirmavam que, "de todos os modos de contaminação, a infecção pelo tubo digestivo é a mais eficaz e a que está de melhor acordo com as condições normais de infecção". E explicavam os processos fisiológicos que propiciariam a disseminação do bacilo ingerido para o sistema respiratório: com a idade, "a reação defensiva ganglionar sendo muito menos ativa, os bacilos são mais geralmente levados, com os leucócitos que os englobam, à grande circulação linfática e pela artéria pulmonar ao pulmão”. Desse modo, eles expressavam sua convicção quanto à "tuberculose pulmonar primitiva do adulto" ser "no mais das vezes de origem intestinal". ${ }^{2}$

É incerto, porém possível, que um acontecimento anterior e alheio à polêmica - mas envolvendo seus principais antagonistas - tenha contribuído para a animosidade com que ela foi travada em São Paulo. Em março de 1902, ao transmitir para Sérgio Meira a presidência da Sociedade de Medicina e Cirurgia, Arnaldo Vieira de Carvalho proferiu discurso avaliando a intervenção médica nas questões de saúde da cidade durante sua gestão. Ao se referir à vacinação contra a varíola, atribuiu as reclamações contra a deficiente resposta imune na capital a falhas no processo de inoculação, como a falta de assepsia do instrumento vacinador e da região inoculada. Victor Godinho considerou 
que a crítica desmerecia a atuação dos médicos que, como ele, exerciam a função de inspetor sanitário na cidade, e dirigiu ao Instituto Vacinogênico, há vários anos sob a direção do próprio Arnaldo Vieira de Carvalho, a crítica pela baixa efetividade da polpa vacinal produzida.

Ademais, o discurso de Arnaldo Vieira de Carvalho contemplava ainda uma menção negativa ao risco de transmissão da tuberculose através do leite, a qual também foi objeto de reparo por Victor Godinho. Com réplicas e tréplicas, todo o debate foi divulgado pela Revista Médica de São Paulo (Godinho, 1902a, 1902b; Carvalho, 1902; São Paulo, 1902a, 1902b). Apesar de "a cautela da gravidade" reduzir "o sabor da controvérsia", a polêmica foi travada "dentro das normas do fairplay, mas não muito", na avaliação de Antonio da Palma Guimarães (1967), biógrafo de Arnaldo Vieira de Carvalho.

\section{O debate na Sociedade de Medicina e Cirurgia de São Paulo}

Entre dezembro de 1902 e março de 1903, as sessões quinzenais da Sociedade de Medicina e Cirurgia de São Paulo foram dedicadas ao debate envolvendo tuberculose e leite de vaca. O acompanhamento das diversas intervenções consignadas em ata ilustra com bastante propriedade a dinâmica das polêmicas médicas sobre várias outras questões no período. Os antagonistas procuravam congregar as evidências que sustentassem seus pontos de vista. Argumentos colhidos na literatura, relatos de observação e idéias iam sendo arrolados, na expectativa de atrair possíveis pontos de consenso. $\mathrm{Na}$ ausência de experimentação e observação sistemática, o debate adquiria uma feição doutrinária, e a documentação insuficiente arrolada pelas partes dava ensejo a incisivas refutações.

O início do debate foi suscitado por Sérgio Meira, presidente da sociedade, que comissionou Arnaldo Vieira de Carvalho, Arthur Vieira de Mendonça e Ulysses Paranhos, solicitando-lhes a elaboração de relatório preliminar que servisse de base para a discussão coletiva do tema. Como pauta, propunha as seguintes questões:

1. A injeção de tuberculina constitui sempre em todos os casos prova cabal e única para o diagnóstico da tuberculose?

2. Quais suas vantagens e inconvenientes?

3. No estado atual da ciência, existe identidade entre tuberculo se humana e bovina?

4. Existe perigo de transmissão da tuberculose do homem ao boi e vice-versa? (Carvalho, 1903a).

O parecer inicial elaborado por Ulysses Paranhos procurava reunir indicações da literatura médica internacional e pendia expressamente para a capacidade de transmissão da tuberculose bovina ao homem. No entanto, possivelmente por influência de Arnaldo Vieira de Carvalho, o parecer procurava contornar a questão relativa à etiologia da doença 
em seres humanos e em bovinos, se envolvia ou não um único agente, e estendia-se sobre os critérios e cuidados a serem observados para que a aplicação do teste de tuberculina obtivesse resultado confiável. E, como medida de cautela, concluía apregoando a necessidade de rigor das medidas profiláticas:

Diante de um problema de profilaxia sanitária, gravíssimo como é o da tuberculose, quando houver dúvidas sobre os seus modos de transmissão, é de obrigação do higienista, por dever de responsabilidade e consciência, adotar a hipótese mais pessimista. Muitas vezes, a supressão rápida de certas medidas de prevenção, sem prova absoluta de sua inutilidade, traz os resultados mais funestos e lutuosos para a saúde das coletividades. É esse nosso parecer, salvo melhor juízo (Paranhos, 1903).

Embora tenha subscrito o relatório de Ulysses Paranhos, Arnaldo Vieira de Carvalho (1903a) sublinhou que sua adesão era feita "com reservas" e emitiu voto discordante em separado, o qual publicou na imprensa diária antes mesmo que a associação médica houvesse apreciado a matéria, o que pode ter contribuído para a animosidade do debate. Em seu parecer, ele concentrou-se na atribuição de incerteza ao teste da tuberculina - "a tuberculina falha, falha miseravelmente em bom número de casos" - e na suposição de inocuidade do leite contaminado - "a ebulição tal qual é praticada habitualmente não mata o bacilo"; "a esterilização que mata o bacilo torna o leite absolutamente impróprio para a alimentação", sendo "preferível, pois, nada fazer".

Carvalho (1903b) refutava a veracidade dos relatos de aquisição da doença via leite de vacas tuberculosas, sublinhando a multiplicidade dos meios de transmissão: os doentes poderiam ter "absorvido poeira de escarros tuberculosos nos carros, nos bondes, nas ruas, nos colégios, nas igrejas". E concluía que "as vacas tuberculosas são as mais inocentes do mundo", não se justificando, portanto, "sobrecarregar esse alimento com proibições e condenações que nem a ciência nem a observação médica justificam". Acrescentava ele:

O homem nada tem a temer dos bovídeos quanto ao contágio da tuberculose. ... Ele tem, ao contrário, tudo a temer do homem tuberculoso, que é a causa única da propagação da bacilose humana. ... A injeção de tuberculina não é uma prova cabal e única da tuberculose quando determina reações. A tuberculina tem a vantagem da rapidez, mas tem os inconvenientes da incerteza. Não há identidade entre a tuberculose humana e bovina. Não há perigo de transmissão do homem ao boi, nem do boi ao homem. Por conseqüência, tudo quanto temos feito nesse sentido tem sido em pura perda. Combatemos fantasmas.

Na sessão de 15 de janeiro de 1903, foi efetuada a leitura dos relatórios de Ulysses Paranhos e Arnaldo Vieira de Carvalho (São Paulo, 
1903b). A segunda comunicação, no entanto, foi aparteada de modo incisivo por Affonso de Azevedo, que propôs elaborar "análise crítica" de seu parecer, no qual refutaria "ponto por ponto as proposições avançadas" por Arnaldo Vieira de Carvalho, demonstrando "que suas afirmações carecem de fundamento científico".

O debate foi retomado na sessão seguinte, em 3 de fevereiro, quando Victor Godinho apresentou comunicação pessoal sobre a matéria, reforçando o parecer original de Ulysses Paranhos (São Paulo, 1903c; Godinho, 1903). Apoiado na ascensão intelectual do colega, Ulysses Paranhos declarou sua adesão ao novo parecer e solicitou que o mesmo passasse a servir de referência para a discussão da sociedade. Ausente por motivo de viagem, Arthur Vieira de Mendonça absteve-se do debate.

Na sessão de 16 de fevereiro, Affonso de Azevedo (1903) apresentou extenso parecer sobre a matéria, no qual cumpria a promessa de polemizar com Arnaldo Vieira de Carvalho. Ele exacerbava as posições:

Quero crer, senhores, que o dr. Arnaldo não conheça a observação em questão. ... Como vedes, mais uma vez foi infeliz o meu colega dr. Arnaldo. Cada afirmativa do ilustrado colega é mais um erro que junta aos muitos de que está içado o seu relatório. Termino minha crítica ao parecer do dr. Arnaldo dizendo: colegas, o parecer apresentado nessa sociedade sobre a tuberculose bovina pelo dr. Paranhos é perfeitamente fundado em dados científicos, e não em fantasmas.

Como era de se esperar, a intervenção acirrou as posições e esquentou o debate. A sessão foi tumultuada pelo calor da discussão, e a deliberação foi protelada para a reunião seguinte, realizada em 2 de março. Nessa ocasião, a discussão foi formalmente encerrada, com a aprovação de quatro pontos conclusivos retirados do relatório de Victor Godinho. Seu parecer original continha ainda dois quesitos relativos ao consumo de carne bovina, os quais foram suprimidos em função das dúvidas que persistiam a respeito. Com isso, a deliberação da sociedade ficou assim sintetizada:

1. A tuberculina é o melhor meio de reconhecer a tuberculose bovina. Seus resultados são quase infalíveis.

2. No estado atual da ciência, não se pode afirmar se a tuberculose do gado é inteiramente idêntica à tuberculose humana; podese, porém, assegurar que a tuberculose humana é a origem mais comum da tísica.

3. Embora haja dúvidas sobre a unidade das tuberculoses bovina e humana, como existem várias experiências denunciando a presença do bacilo de Koch no leite e o poder infectante deste alimento, é de toda a prudência que se continue a ferver o leite antes de ser usado. 
4. Nos estábulos deve-se continuar a fazer a segregação do gado tuberculoso, servindo-se para isso das injeções de tuberculina (São Paulo, 1903d).

\section{Desdobramentos do debate}

Nos anos que se seguiram ao debate, novas intervenções reforçaram a convicção preponderante no meio médico quanto à necessidade das medidas de controle sanitário do leite (Carini, 1910; São Paulo, 1911). Em 1907, o 6o Congresso Médico Brasileiro, realizado em São Paulo, teve uma sessão específica dedicada à tuberculose humana, a qual foi coordenada por Emílio Ribas e incluiu considerações sobre a questão da possível transmissão através do leite de vacas tuberculosas. Mas a dissensão entre profissionais de saúde e criadores de gado persistiu, mesmo depois que o pensamento médico deu mostras de definição no sentido de validar a hipótese da viabilidade de transmissão da tuberculose bovina para o ser humano. E embora os médicos tentassem ampliar as determinações do controle sanitário de alimentos, os pecuaristas continuaram reivindicando junto às autoridades civis o abrandamento das medidas.

Entre 1910 e 1912, a Sociedade de Medicina e Cirurgia de São Paulo voltou a discutir o tema, em função de a Sociedade de Agricultura ter votado moção contrária à lei que obrigava o abate do gado tuberculoso. Conquanto os fazendeiros considerassem a medida prejudicial e adotassem o argumento da defesa dos produtores nacionais, as intervenções médicas foram unânimes em cobrar a manutenção da medida, e inclusive voltaram a reivindicar a pasteurização do leite para consumo humano (São Paulo, 1913; Carini, 1910), iniciativa que, no entanto, não foi adotada no período.

A prolongada persistência manifestada pelos pecuaristas no confronto com os direcionamentos propostos pelos médicos no controle sanitário de alimentos indica que eles não participavam do consenso que surgiu entre a categoria médica quanto à polêmica sobre tuberculose e leite. Affonso de Azevedo também voltou ao tema nas sessões da sociedade, trazendo as evidências mais recentes da literatura médica internacional, as quais reforçavam a conviç̧ão da transmissibilidade da doença entre as espécies (São Paulo, 1911).

Arnaldo Vieira de Carvalho (1912a) ainda voltou ao tema em 1912, para reiterar os cuidados especiais que a aplicação do teste da tuberculina exigiria para a obtenção de resultados confiáveis. O fato de ele continuar levantando suspeitas ao recurso diagnóstico usualmente empregado - ao mesmo tempo que não retomava os argumentos do decênio anterior, quando postulava a inocuidade do leite contaminado - é sugestivo de uma retração de sua posição no debate, ou ao menos de sua disposição em não romper com o consenso já formado no meio profissional. 
${ }^{3}$ Buscando esclarecer sua posição nesse debate, os autores do presente artigo tentaram consultar o acervo de anotações autógrafas, cartas, ofícios e outros manuscritos de Adolpho Lutz, mantidos sob a guarda do Setor de Arquivo do Instituto Adolfo Lutz. No entanto, o péssimo estado de conservação desse material inviabilizou a incorporação de seu conteúdo ao estudo.
Apesar disso, e consoante sua manifesta predisposição favorável aos interesses da pecuária paulista, no mesmo período, ele ocupou sua coluna no jornal O Estado de S. Paulo para discorrer sobre outros aspectos de interesse para a produção local de leite e propor medidas que a favorecessem. Em especial, solicitou redução de impostos de importação do farelo de trigo utilizado no preparo da ração animal (Carvalho, 1911); defendeu o cruzamento de raças bovinas nacionais com as européias, com o intuito de aumentar a produtividade dos rebanhos paulistas (idem, 1912b); propugnou a diversificação da monocultura, através da criação de gado nas fazendas de café e protestou contra a proposição na Câmara Municipal de medidas de controle da qualidade do leite relativas a padrões de acidez e teor de gordura do produto, as quais ele acusava de beneficiar a importação do produto (idem, 1915).

Resta ainda esclarecer e documentar qual teria sido a efetiva participação de Adolpho Lutz na polêmica sobre tuberculose e leite. Embora não tenha se manifestado nos debates da sociedade e nas publicações médicas sobre o tema, na condição de diretor do Instituto Bacteriológico, ele foi o responsável pelos exames necroscópicos comprobatórios da tuberculose bovina primariamente identificada pelo teste da tuberculina.

A literatura preservou indicações de que Lutz teria se envolvido em conflito direto tanto com pecuaristas como com médicos que postulavam a inocuidade do leite contaminado. Albuquerque (1950) afirmou que a questão da tuberculose bovina "motiva a última das grandes campanhas de interesses e ódios que Lutz teve de enfrentar", antes de sua transferência para o Rio de Janeiro, em 1908. A tradição oral do Instituto Bacteriológico preservou a lembrança de suas desavenças com médicos e pecuaristas paulistas, com Arnaldo Vieira de Carvalho em especial, sobre a questão envolvendo tuberculose e leite, sugerindo inclusive que este teria sido um fator preponderante de sua decisão de aceitar o convite de Oswaldo Cruz para se transferir para o Rio de Janeiro e atuar no Instituto Seroterápico de Manguinhos (Antunes et al., 1992).

Bruno Rangel Pestana (1942), em discurso comemorativo dos cinqüenta anos do Instituto Bacteriológico, sugeriu, sem explicitar referências, que o "cirurgião mais ilustre e o clínico mais distinto" da classe médica paulista teriam publicamente exigido a demissão de Adolpho Lutz, "a bem do serviço público, ... porque ele condenara, no interesse da saúde do povo de São Paulo, vacas leiteiras tuberculosas". ${ }^{3}$

\section{Conclusão}

Com o tempo, o conceito de que a tuberculose bovina é de fato transmissível ao homem e a outros animais prevaleceu no pensamento médico. Foi constatada a participação de espécies distintas do gênero Mycobacterium na etiologia da tuberculose humana (Mycobacterium 
Agradecimentos a Maria Candelária Volponi Moraes, Patrícia Lira e Camila Brandi Souza, do Departamento do Patrimônio Histórico da Secretaria Municipal da Cultura de São Paulo, pelo apoio na localização de documentos. tuberculosis) e bovina (Mycobacterium bovis). Ambas as espécies, no entanto, foram identificadas como responsáveis por infecção no ser humano (Silverstein et alii, 1994).

Em nossos dias, medidas sistemáticas aplicadas à pecuária, como os testes de rotina para o diagnóstico de diversas doenças nos rebanhos e a pasteurização do leite, reduziram o risco de tuberculose humana por $M$. bovis. No entanto, este ainda é um problema para os países e regiões mais submetidos à privação social, nos quais essas medidas não foram adotadas de modo mais efetivo.

Apesar de existirem medidas de prevenção e quimioterapia antituberculosa eficaz, tem-se relatado que a transmissão de tuberculose bovina para o ser humano é crescente em todo o mundo, relacionandose não apenas ao padrão socioeconômico, mas também a condições de imunossupressão, como a Aids (O'Reilly et al., 1995).

A polêmica sobre a viabilidade da transmissão da tuberculose via leite de vaca em São Paulo reflete um momento delicado e complexo da história da medicina no Brasil, no qual ela esteve sob pressão externa e interna por parte de interesses de ordem econômica. Representantes ilustres da própria categoria fizeram repercutir no meio profissional as demandas conjunturais da pecuária paulista e expressaram proposições de interesse dos criadores em termos de argumentação médica.

O significado da intromissão de interesses econômicos no pensamento médico pode ser ainda melhor apreciado quando se recorda que, no período em que se desdobrava o debate, a sociedade paulista pautava-se por uma economia preponderantemente rural, e o ciclo da cafeicultura atingia seu apogeu (Morse, 1970).

Considerada sob outro ângulo, poder-se-ia dizer que a polêmica sobre tuberculose e leite marca igualmente um evento bastante expressivo, no qual o pensamento médico repercutiu com especial intensidade nas esferas legislativa e institucional, no momento mesmo em que suas concepções passavam pelo crivo do debate e se firmavam. O consenso surgido da polêmica deu origem a diversos documentos legais e subsidiou inúmeros debates legislativos durante as duas primeiras décadas do século XX. Nesse sentido, e ainda que nem todas as suas propostas (como a pasteurização do leite) tenham sido implementadas, pode-se dizer que os debates médicos tiveram conseqüências tangiveis para as decisões oficiais relativas à saúde pública paulista.

Sugere-se que pesquisas posteriores focalizem dimensões que não foram contempladas no presente estudo, como as posturas assumidas pelos criadores no enfrentamento com os médicos, e busquem reconstituir o debate médico e suas conseqüências em outras unidades da federação, contribuindo assim para o esclarecimento do processo histórico de afirmação da autoridade médica sobre assuntos relativos à organização da sociedade. 


\section{REFERÊNCIAS BIBLIOGRÁFICAS}

Albuquerque, Maria S. $\quad$ 'Dr. Adolpho Lutz'. Revista do Instituto Adolfo Lutz, no 10, pp. 9-30. 1950

Antunes, José L. F. et al. 1999

'Tuberculosis in the twentieth century: time-series mortality in São Paulo, Brazil, 1900-97'. Cadernos de Saúde Pública, no 15, pp. 463-76.

Antunes, José L. F. et alii (org.) 1992

Azevedo, Affonso de 1903

Brasiliense, Américo 1923

Burgos, Coriolano de 1900

Instituto Adolfo Lutz: 100 anos do laboratório de saúde pública. São Paulo, Letras e Letras, 280p.

'Tuberculina e tuberculose bovina'.

Revista Médica de São Paulo, nº 6, pp. 97-103.

'Dr. Victor Godinho'.

Anais Paulistas de Medicina e Cirurgia, nํ11, pp. 14-5.

'A liga contra a tuberculose'.

Revista Médica de São Paulo, no 3, pp. 239-46.

Calmette, Albert L. C.

'Origem intestinal da tuberculose pulmonar'.

et al.

1906

Carini, Antonio

Revista Médica de São Paulo, no 9, pp. 308-9.

'A questão do leite em São Paulo'.

Revista Médica de São Paulo, nำ13, pp. 465-6.

Carvalho, Arnaldo V. de 1915

'A questão do leite'.

O Estado de S. Paulo, 7.4, 11.4, 14.4 e 19.4 .

Carvalho, Arnaldo V. de $1912 \mathrm{a}$

'A tuberculina'.

Revista Médica de São Paulo, nº 15, pp. 151-2.

Carvalho, Arnaldo V. de $1912 \mathrm{~b}$

'Um problema de pecuária paulista'.

O Estado de S. Paulo, 6.8, 20.8 e 25.8.

Carvalho, Arnaldo V. de 1911

'De Re Rustica'.

O Estado de S. Paulo, 7.1 e 27.1.

Carvalho, Arnaldo V. de $1903 a$

Carvalho, Arnaldo V. de $1903 \mathrm{~b}$

'A tuberculose bovina é transmissível ao homem e vice-versa?'.

O Estado de S. Paulo, 18.1.

'A tuberculose bovina é transmissível ao homem e vice-versa?'. Revista Médica de São Paulo, nº 6, pp. 41-5.

Carvalho, Arnaldo V. de 1902

'A vacinação em São Paulo'.

Revista Médica de São Paulo, no 5, pp. 173-4.

Ferreira, Clemente 1902

Godinho, Victor 1903

Godinho, Victor $1902 a$

Godinho, Victor 1902b

Godinho, Victor 1900

Godinho, Victor et al. 1899a

'O problema da tuberculose em Portugal e no Brasil'. Revista Médica de São Paulo, nº 5, pp. 41-9.

'Tuberculina e tuberculose'.

Revista Médica de São Paulo, no 6, pp. 61-9.

'A vacinação em São Paulo'.

Revista Médica de São Paulo, nํ5, pp. 136-7.

'Ao dr. Arnaldo Vieira de Carvalho'.

Revista Médica de São Paulo, nํ5, pp. 174-7.

'A tuberculose sob o ponto de vista social'.

Revista Médica de São Paulo, no 7, pp. 76-84.

'Tuberculose: contágio, curabilidade, tratamento higiênico e profilaxia. IV. Tuberculose por ingestão'. Revista Médica de São Paulo, 2(2): 36-8.

Godinho, Victor et al. $1899 \mathrm{~b}$

'Tuberculose: contágio, curabilidade, tratamento higiênico e profilaxia. XIX. Profilaxia da tísica pulmonar'. Revista Médica de São Paulo, nº 2, pp. 110-20. 


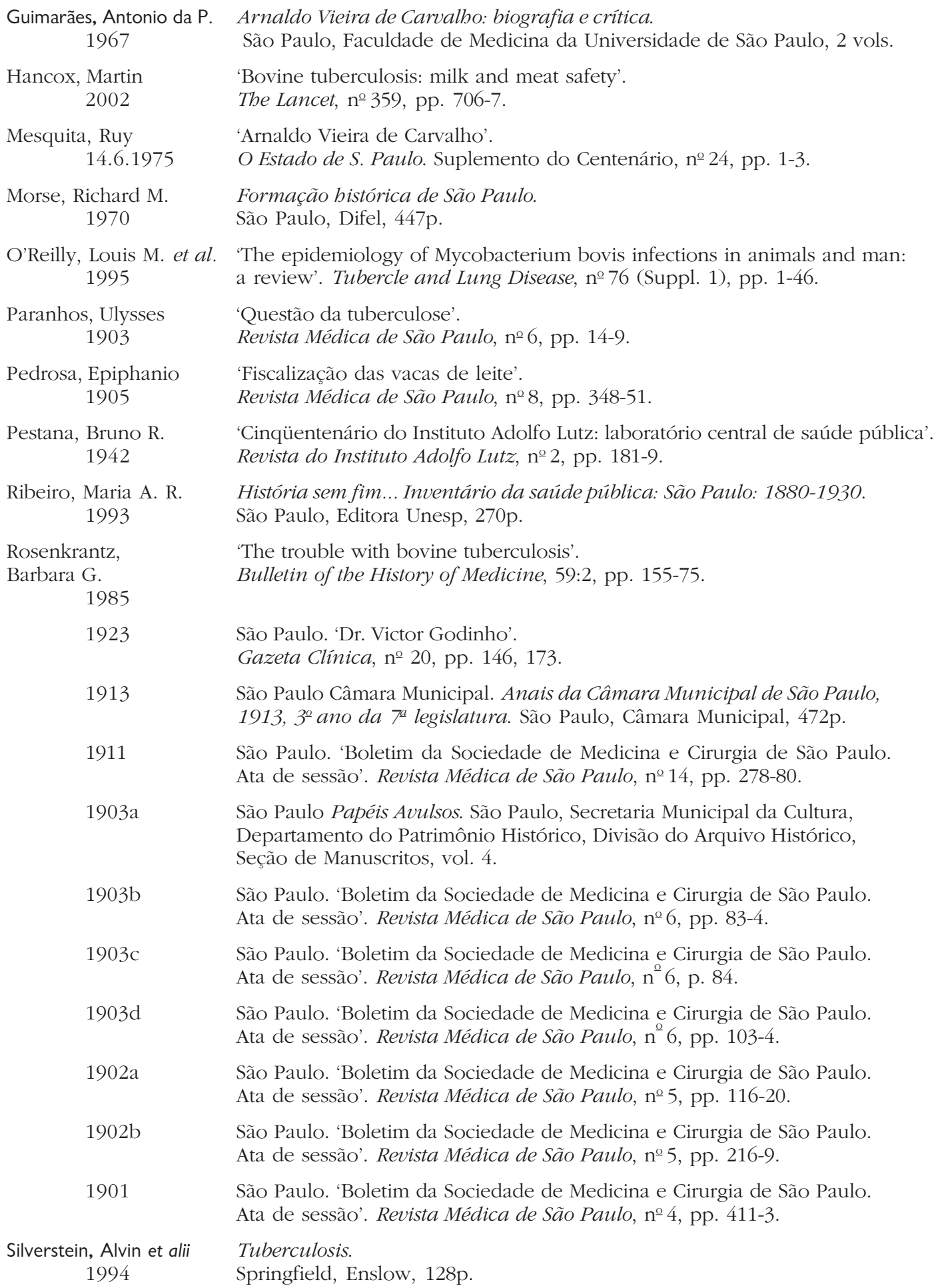

Recebido para publicação em setembro de 2001.

Aprovado para publicação em maio de 2002 